\title{
Optimising extraction of extracellular polymeric substances (EPS) from benthic diatoms: comparison of the efficiency of six EPS extraction methods
}

\author{
Eri Takahashi ${ }^{\mathrm{a}}$, Jérôme Ledauphin ${ }^{\mathrm{b}}$, Didier Goux ${ }^{\mathrm{c}}$ and Francis Orvain ${ }^{\mathrm{a}, ~}{ }^{*}$
}

\begin{abstract}
a UMR 100 IFREMER-Université de Caen Basse-Normandie 'Physiologie et Ecophysiologie des Mollusques Marins (PE2M)', Laboratoire de Biologie et Biotechnologies Marines, Esplanade de la Paix, B.P. 5186, 14032 Caen Cedex, France.

${ }^{\mathrm{b}}$ Laboratoire ERPCB-EA 3914, Boulevard Maréchal juin, Campus 2, 14032 Caen Cedex, France.

c Centre de microscopie appliquée à la biologie, Université de Caen Basse-Normandie, IFR 146, Campus 1, Esplanade de la Paix, B.P. 5186, 14032 Caen Cedex, France.
\end{abstract}

\section{*: Corresponding author : F. Orvain, email address : Francis.Orvain@unicaen.fr}

\begin{abstract}
:
There is no universal method that can be applied to extract bound extracellular polymeric substances (EPS) from benthic diatoms of intertidal sediments without causing cell lysis. Six extraction methods were tested on a diatom culture of Navicula jeffreyi to establish the best compromise between high yields of carbohydrate extraction and minimum cell lysis. Extraction with distilled water provoked cell lysis (as already known). The five other extraction methods (dowex resin, artificial seawater of half salinity and extractions after pretreatment with gluteraldehyde by three methods: water, dowex water and dowex buffer) did not provoke cell lysis as shown by transmission electronic microscopy. This result was confirmed by the minimum release of internal compounds (protein, ATP) and by the low proportions of glucose in dowex-extracted EPS compared with the water-extracted EPS, from which the high glucose content must be inferred as contamination by the chrysolaminaran. The extraction with dowex resin resulted in the second-highest concentration of carbohydrate after the water extraction and the EPS were especially rich in deoxy sugars, hence increasing the hydrophobic feature of these substances. For these reasons, we recommend extraction with dowex, which is also the best method for extracting bound EPS from other biofilms such as in activated sludges.
\end{abstract}

Keywords: biofilm, cell lysis, dowex, GCMS analysis, immunostaining, immuno-staining, intertidal sediments, Navicula jeffreyi, protein, transmission electron microscopy 


\section{Introduction}

Benthic diatoms are an important component of microphytobenthos inhabiting the intertidal mudflats by constituting biofilms at the sediment surface (Decho 1990; Wingender et al. 1999). These diatoms are responsible for the production of Extracellular Polymeric Substances (EPS), which have high contents of carbohydrates (de Brouwer et al. 2002; Chiovitti et al. 2003; Underwood et al. 2004). Excretion of EPS by diatoms provides a food source for heterotrophic organisms and affects the erodability of biofilms (de Brouwer et al. 2002; Underwood et al. 2004; Bellinger et al. 2005). Production rates of EPS differ as a response to the environmental condition as well as the growth stage of the diatoms (Smith and Underwood 2000; Underwood et al. 2004; Hanlon et al. 2006). The monosaccharide composition of these exopolymers varies as a function of the physiological status of the cells (Bellinger et al. 2005; Abdullahi et al. 2006; Hanlon et al. 2006). Effective EPS extraction and measurement are critical in studying the characteristics of the EPS to understand the roles played by EPS in the ecosystem (Wingender et al. 1999).

Numerous methods for EPS extraction have been tested, however, there is no universal extraction method for EPS to date. Extraction protocols in the literature can be divided into two groups: physical (sonication, cationic dowex resin, heating) and chemical methods (Ethylen Diamine Tetracetic Acid, $\mathrm{NaOH}$, formaldehyde, water) (Nielsen and Jahn 1999; Comte et al. 2006). Some recent studies conducted on sludge samples have used combinations of physical and chemical methods of extraction and fixatives such as glutaradehyde and formaldehyde protecting the cells during EPS extraction (Liu and Fang 2002; Azeredo et al. 2003; Comte et al. 2006) but such fixatives were shown to interfere with EPS measurement by overestimation of the EPS or by reacting with the EPS and changing their characteristics (Underwood et al. 1995; Comte et al. 2006).

In some studies, the extraction method is supported by testing of cell lysis as listed by Nielsen and Jahn (1999). Testing methods include measurement of protein quantity, detection of DNA or ATP, and microscopic observation of cells (Nielsen and Jahn 1999; Azeredo et al. 2003; Chiovitti et al. 2004). The microscopic observation can include simple staining with Alcian Blue to determine cell mortality and integrity of membranes (Staats et al. 1999) or immuno-staining of the chrysolaminaran, also known as 1,3- $\beta$-D-glucan, found in the vacuoles of the diatoms (Chiovitti et al. 2003; 2004).

To avoid contamination of EPS with the intracellular materials, it is important to find a method that can extract high yields of carbohydrate without causing cell lysis (Liu and Fang 2002; Azeredo et al. 2003; Chiovitti et al. 2003; 2004). Previous studies such as 
those by Chiovitti et al. (2003; 2004) and de Brouwer and Stal (2004) have shown that the extraction methods need to be adjusted according to the species and strains of diatoms used. For example, the plasmidic membranes of species Phaeodactylum tricornutum, Cylindrotheca fusiformis, Craspedostauraos australis, Pinnularia viridis and Thalassiosira pseudonana showed little resistance to the incubation in warm freshwater at $30^{\circ} \mathrm{C}$ for 1 hour (Chiovitti et al. 2003; 2004), whilst a strain of Cylindrotheca closterum showed little evidence of cell lysis with this extraction method (de Brouwer et al. 2002).

de Brouwer and Stal (2004) argued that even if there is evidence of cell lysis and release from intracellular glucans with the water extraction, the separation of Low Molecular Weight (LMW) and High Molecular Weight (HMW) materials by overnight precipitation in cold $-20^{\circ} \mathrm{C}$ ethanol $(75 \%)$, isolates the EPS in the HMW fraction and prevents contamination by internal storage carbohydrates that do not precipitate in cold ethanol and are found in the LMW fraction. This size fractionation method can be used to separate the HMW fraction to limit the contamination of intracellular carbohydrates (de Brouwer and Stal 2004). Bound EPS, however, could also consist of LMW carbohydrates (de Brouwer and Stal 2001), and to obtain the accurate description of all fractions of these polymers such as monosaccharide composition, nature of the macromolecules and rheological properties (defined as the resistance and viscosity forces of the sediment gel), there is still a need to optimize the extraction method of EPS without contamination from internal components.

The aim of the current study was to optimize the EPS extraction from diatom cultures without lysing the cells. It focused on the comparison between combinations of both physical and chemical extraction procedures of EPS, and measured the ATP production and protein quantities. The study further investigated the state of the diatoms after each extraction procedure, using immuno-staining (with monoclonal antibody against chrysolaminaran or $\beta-1,3-D-g l u c a n$ and Transmission Electron Microscopy (TEM). The use of fixatives such as glutaradehyde (GTA) has been clearly shown to affect the accuracy of EPS analysis (Underwood et al. 1995; Comte et al. 2006). However, in the present study, GTA (Gluteradehyde) was incorporated in the experimental design to compare the difference of ultrastructure between GTA protected cells and non-protected cells during the extraction with dowex and with water. The different extracts were all dialysed $(7 \mathrm{kD})$ to remove the chemical sources of interference such as GTA and to purify the EPS before biochemical analysis. 


\section{Materials and methods}

Diatom cultures. For the extraction of EPS, Navicula jeffreyi (AC 181, strain from the Algobank collection, University of Caen) was grown in F/2 media at a constant light and temperature of $16^{\circ} \mathrm{C}$. For biological replicates, cultures were grown in three separate flasks with volumes of $75 \mathrm{~mL}$ in each flask.

Extraction protocols. For each extraction method, $10 \mathrm{~mL}$ of cell culture was used with three biological replicates of each. The sample was first centrifuged (10 min, $2000 \mathrm{~g}$ ) to measure the spent culture medium carbohydrates which are considered as colloidal EPS (de Brouwer et al. 2002; Chiovitti et al. 2003; Underwood et al. 2004). In the sequential extractions of the different fractions of EPS, the second step consists of extraction of bound EPS using warm freshwater $\left(1 \mathrm{~h}, 30^{\circ} \mathrm{C}\right)$. In previous studies (Wustman et al. 1997; Bellinger et al. 2005; Hanlon et al. 2006), the extraction with water was performed at a high temperature of $95^{\circ} \mathrm{C}$. To optimize this step of EPS extraction without cell lysis, six methods and a control were tested as listed (Fig. 1). In the case of extraction using the cation exchange resin (Dowex Marathon $\mathrm{C}, \mathrm{Na}^{+}$; Sigma-Aldrich), the quantity used was $50 \mathrm{~g} \mathrm{~g}^{-1}$ of biomass (Liu and Fang 2002) and phosphate buffer $(20 \mathrm{~mL})$ was used as the extraction media tubes were stirred during 1 hour at $4^{\circ} \mathrm{C}$. After centrifugation (10 min, $3500 \mathrm{~g}$ ), pellets were resuspended in $2 \mathrm{~mL}$ of distilled water (Fig. 1) by vortexing. In three out of six extraction methods, cells were fixed with glutaradehyde (GTA; 1.8\% v/w) (Azeredo et al. 2003) prior to extraction. The use of this fixative protects the cells against cell lysis.

A pilot study was conducted to test for the effects of sonication at $40 \mathrm{~W}$ using salt water and half the salinity of salt water. Cells were then observed using TEM analysis. These results clearly showed cell lysis, hence extraction by sonication was not included in this study.

Immuno-staining and TEM analysis. After treating the diatoms and removal of the extracts, cells were fixed with $2.5 \%$ gluteraldehyde in 0.36 cacodylate buffer $(\mathrm{pH} 7.2)$ containing $0.26 \mathrm{M}$ sucrose. Cells were then washed three times in $0.1 \mathrm{M}$ cacodylate buffer containing decreasing concentrations of sucrose $(0.25 \mathrm{M}, 0.12 \mathrm{M}$, the last wash without sucrose) for 15 min each time, followed by post-fixation in $2 \%$ osmium tetroxide in $0.1 \mathrm{M}$ cacodylate buffer for $1.5 \mathrm{~h}$ at $4^{\circ} \mathrm{C}$. After washing in distilled water, cells were centrifuged in agar, dehydrated in a graded ethanol series and embedded in Epon resin. Ultrathin sections were collected onto nickel grids and immuno-stained as described by Chiovitti et al. $(2003,2004)$. Briefly, grids were washed with blocking 
solution, composed of $1 \%$ bovine serum albumin in PBS (PBS: $120 \mathrm{mM} \mathrm{NaCl}, 2.7 \mathrm{mM}$ $\mathrm{KCl}, 10 \mathrm{mM}$ phosphate buffer, $\mathrm{pH} 7.4$ ) for 30 minutes and incubated in $30 \mu \mathrm{g} \mathrm{m}^{-1}$ of primary antibody (1,3- $\beta$-D-glucan mouse IgG antibody; Biosupplies Australia Pty Ltd) for four hours. The grids were rinsed three times, five minutes each, with blocking solution and incubated in 1:40 dilution of secondary antibody (Aurion Conventional Gold Reagent; Biovalley) for overnight at $4^{\circ} \mathrm{C}$. The grids were rinsed three times with filtered PBS for five minutes, and further rinsed three times with filtered distilled water for 30 seconds. Grids were observed using transmission electron microscope (TEM; Jeol 1011, camera SIS megaview III, logical analysis 5).

To perform the standard staining procedure, two sets of negative control grids were prepared. For the first negative control, water was used in place of the primary antibody, whilst in the second negative control water was used in the place of the secondary antibody.

After observation of immunostained cells, sections were contrasted by applying uranil acetate and Reynold's lead citrate. When the TEM grids were contrasted, it was difficult to observe the colloidal staining, hence the images were investigated for staining before contrasting, and condition of the cells was further investigated after the cells were contrasted. The percentage of intact cells, damaged cells and empty cells were recorded, where intact cells referred to those cells in which internal structure was clearly visible.

Carbohydrate. The extracts were dialyzed overnight against milliQ water using membrane $(7 \mathrm{kD})$ at $4^{\circ} \mathrm{C}$. A second dialysis was performed overnight to remove the GTA, and was applied for all samples to avoid any variations between the extraction methods. The carbohydrate content was measured using the Dubois method (1956) with glucose as the standard. Briefly, to $0.5 \mathrm{~mL}$ of the dialyzed extract, $0.5 \mathrm{~mL} 5 \%$ phenol and $2.5 \mathrm{~mL}$ sulfuric acid was added and vortexed. Measurement was read after 30 minutes using spectrophotometer at $485 \mathrm{~nm}$ with glucose as a standard for calibration curve.

Protein. Aliquots of extracts $(0.3 \mathrm{~mL})$ after dialysis against distilled water $(7 \mathrm{kD})$ were taken for protein analysis. These samples were tested for protein using the Lowry Assay (Lowry et al. 1951) with BSA as standards. Briefly, $5 \mathrm{~mL}$ copper sulfate: sodium potassium tartrate solution was added to 400 ul of the extract. After exactly 20 minutes, $1 \mathrm{~mL} 0.2 \mathrm{~N}$ Folin reagent was added. Samples were incubated for 30 minutes and the absorbance was measured using spectrophotometer, at a wavelength of $750 \mathrm{~nm}$. 
ATP analysis. Aliquots of $100 \mu \mathrm{L}$ of each of the extracts, prior to dialysis, were used for ATP measurement. The dialysis that was efficient to purify carbohydrate and protein extracts (from GTA contamination) cannot be performed to assess the quantity of ATP. For ATP analysis, Adenosine 5'triphosphate bioluminescent Assay Kit (Sigma-Aldrich) was used. Briefly, $100 \mu \mathrm{L}$ ATP mix (1:25 dilution) was used for $100 \mu \mathrm{L}$ samples and luminescence was measured using a bioluminometer-MITHRAS LB-940 (Azeredo et al. 2003).

Monosaccharide composition by GC/MS (Gas Chromatography/Mass Spectrometry analysis). Extracted samples were dialyzed overnight at $4^{\circ} \mathrm{C}$ and freeze dried prior to preparation for GCMS analysis. Protocols by Abdullahi et al. (2006) and Bellinger et al. (2005) were followed with slight alteration. Briefly, samples were hydrolysed using $2 \mathrm{M}$ TFA $(200 \mu \mathrm{L})$ at $121^{\circ} \mathrm{C}$ for $3 \mathrm{~h}$. These were dried at $40^{\circ} \mathrm{C}$ and saponified using $200 \mu \mathrm{l} 1 \mathrm{M}$ $\mathrm{NH}_{4} \mathrm{OH}$ for two hours, then reduced using $500 \mu \mathrm{L} 0.5 \mathrm{M} \mathrm{NaBH}{ }_{4}$ in DMSO (to be defined) for $2 \mathrm{~h}$. Fifty microlitres of $18 \mathrm{M}$ acetic acid were then added. Samples were acetylated using $100 \mu \mathrm{L}$ 1-methylimidazole, $1 \mathrm{~mL}$ acetic anhydride and incubated for 10 minutes. Samples were quenched with $2.5 \mathrm{~mL}$ milliQ water and acetylated sugars were extracted in $500 \mu \mathrm{L}$ dichloromethane. After concentrating the extracts to $100 \mu \mathrm{L}$, they were stored at $-20^{\circ} \mathrm{C}$. Alditol acetates were separated on a fused silica capillary column (SGE BP-20, $50 \mathrm{~m} \times 0.25 \mathrm{~mm} \times 0.25 \mu \mathrm{m}$ ) and detected using a GC-MS system (SATURN 2000R MS, CA, USA). Derivative monosaccharides were identified using their retention times and mass spectra. Quantification was based on response factors of standard monosaccharides that had been subjected to the same procedure.

Statistics. The data of the carbohydrate, protein and ATP were tested for normality of residuals (Kolmogorov-Smirnov test) and homoscedasticity (Bartlett test) and the seven extraction methods were compared using one-way ANOVA. A two-way ANOVA was performed to assess the effects of the treatment and the monosaccharide on the GC/MS results of the proportion of each monomer (considered as fixed factors). In this case, a square root transformation was necessary to satisfy the conditions required for ANOVA.

\section{Results}

Immuno-staining

Immuno-staining using 1,3- $\beta$-D-glucan antibody showed staining the vacuoles (Fig. 2). In the non-contrasted grids, the staining was clearly localized in the vacuoles (Fig. 2A, 
C, D, E, F, G). The staining was seen in cells of all extraction methods except for warm freshwater extraction (Fig. 2B), where the labeled secondary antibodies were found outside of the vacuoles. The two negative controls, in which the primary antibody had been omitted, exhibited no labeling (data not shown).

Empty cells, due to natural mortality of the cells, were seen in all extracts, including the control (Table 1). The percentage of damaged cells was highest when treated with water and lowest when fixed with GTA prior to the extraction by dowex resin (Table 1). The percentage of intact cells was lower with water than that of the other extracts even when protected by GTA (57\%).

The control cells were intact with little cell shrinkage due to the fixation process and the lack of freeze-substitution (Fig. 3A). The contrasted images clearly showed the disruption of the ultrastructure of the cells when treated with freshwater (Fig. 3B). Extraction of dowex resin and half salinity resulted in slight shrinkage, similar to control cells, and internal deformities within the cells. These internal deformity may be attributed to a supplementary effect due to the extraction method (Figs. 3C, 3D).

The clear staining of the vacuoles (Figs. 2C, 2D), however, revealed that deformation of the cells seen in these two extractions do not provoke cell lysis, nor compromise the membrane integrity. These extractions methods thus did not cause release of intracellular carbohydrates. Cells fixed with GTA prior to extraction with dowex resin and water, were well intact, with evidence of cell shrinkage in some cells, similar to the control cells (Fig. 3E).

\section{Carbohydrate measurement}

The amount of carbohydrate showed significant differences between the extraction methods (Fig. 4A, $F_{6,13}=4.09, p=0.016$ ). The highest amount of carbohydrate was extracted from cells treated with water and it was significantly higher than that of the control cells (Tukey test, $T=4.062, p=0.0174$ ). There was significant difference between the carbohydrate extracted using water and all other extraction methods, pretreated with glutaraldehyde (for the 3 Tukey tests, T>0.345, $\mathrm{p}<0.05$ ), but there were no significant differences in carbohydrate between water extraction and both half salinity and dowex extractions (Tukey tests, $\mathrm{T}=3.3242, \mathrm{p}=0.0702$ and $\mathrm{T}=3.024, \mathrm{p}=0.101$; Fig. $4 \mathrm{~A})$. Extraction using dowex, obtained the next highest amount of carbohydrate, followed by half salinity and GTA water extractions. Only water extraction was significantly different from the control treatment (for instance, dowex buffer was the most different from the control after water extraction, Tukey test, $\mathrm{T}=-1.357, \mathrm{p}=0.8142$ ). 


\section{Protein}

Freshwater extraction resulted in high amount of protein and was significantly different to the amount of protein extracted using the other six extraction methods $\left(F_{6,14}=15.77, p\right.$ $<0.001$ and Tukey tests, $T>6.75, p<0.002$ ). Protein extracted from the other six extraction methods did not show significant variation between the methods (Fig. 4B). The ratio of protein:carbohydrate was between 21 and 70. Cells extracted with warm freshwater gave the highest ratio, whilst the other five extraction methods were not different from the control. The second highest protein content was obtained with the half salinity treatment. The standard deviations were also smaller with dowex compared to water and half salinity extraction for protein as well as carbohydrate (Fig. 4).

\section{ATP analysis}

For all three replicates, control cells had the lowest ATP, indicating low amount of cells being lysed during centrifugation (Fig. 5). Samples could not be dialysed prior to ATP analysis as ATP has low molecular weight and will be dialysed with GTA. The effects of GTA reacting with ATP reading was thus prominent and discarded from the analysis (results not shown). When analysis is conducted with removal of the extraction methods with GTA, extraction with distilled water had the highest amount of ATP (Fig. $5)$ and was significantly higher than those extracted from other methods $\left(F_{3,8}=5.18\right.$, $p<0.05)$. Levels of ATP in extraction was significantly different between water extraction and control (Tukey test, $\mathrm{T}=3.377, \mathrm{p}=0.0392$ ) while extraction using dowex and half salinity showed no significant difference to that of the control (Tukey tests, $\mathrm{T}=-0.242$ and $\mathrm{T}=-0.139 ; \mathrm{p}=0.98$ and $\mathrm{p}=0.999$ ).

\section{Analysis of the monomer composition of EPS}

The proportion of each sugar was drastically different between the extraction methods (Fig. 6, 2-way ANOVA, $\mathrm{F}_{42,32}=3.96, \mathrm{p}<0.001$ ). Dominant sugar was glucose in water extraction whilst the dominant sugars were fucose in dowex extraction, xylose in half salinity extraction and glucose in all other extraction methods, including those pretreated with GTA. When comparing between dowex and water extractions, there were significant differences in proportions of rhamnose (Tukey test, $T=-5.518$, $\mathrm{p}=0.038$ ). For fucose and glucose proportions, there were also small differences between dowex and water but they were not significant (Tukey tests, $p=0.213$ and $p=0.327$, respectively). There was a significant difference in amount of rhamnose between half salinity extraction and dowex extraction. For fucose, there was a small difference between half salinity and water $(p=0.135)$. Proportions of other monomers were not significantly different between half salinity and water extractions. The 
proportion of glucose in total bound EPS was of $46 \%$ in water extraction while it was 12 $\%$ in dowex extraction and $26 \%$ in half salinity extraction. The proportions of deoxy sugars were the highest in dowex extraction ( $24 \%$ for fucose and $21 \%$ for rhamnose) whilst lowest in the water extraction. The proportion of glucose was also very high in water-extracts compared to other extraction methods.

\section{Discussion}

For cultured Navicula jeffreyi, it is clear that freshwater at $30^{\circ} \mathrm{C}$ results in cell lysis. It also produced significantly higher amount of EPS, proteins and ATP with the freshwater extraction, compared to the other tested extraction methods. This confirms the results shown by Chiovitti et al. (2003; 2004), where they showed that EPS extracted with freshwater were also made of internal chrysolaminaran. The proportion of glucose was also higher in water-extracts than in other extraction methods.

Extraction using dowex resin resulted in slightly higher carbohydrate, after freshwater extraction. The extracted ATP, protein and glucose contents using dowex resin extraction were not significantly different to those of the control and thus confirmed the lack of cell lysis in this extraction method. Half salinity extraction media showed similar results of carbohydrate and protein levels to that of the dowex extraction. This implies that either dowex and half salinity can be used as an optimal extraction method for EPS. However, only the dowex extraction showed significant difference of glucose proportion in EPS compared with the water extraction and the yield of carbohydrate extraction was higher with dowex with the lowest standard deviation. Dowex resin was shown to be the optimal extraction method and this also compliments previous studies which have successfully extracted EPS from activated sludge (Wingender et al. 1999; Comte et al. 2006).

EPS are ecologically important to explain interactions between diatoms and bacteria and they also have an important role as sediment biostabilizers in intertidal mudflats (Spears et al. 2008). For now, there is no universal method to extract EPS from intertidal sediments and some methods are used for simplicity rather than efficiency. Liu and Fang (2002), Nielsen and Jahn (1999) and Comte et al. (2006) have identified the main methods that are found in the literature for extraction of EPS from bacteria within activated sludges and have shown a high dispersion in terms of extraction yields and composition of extracted EPS. Cation Exchange Resin (Dowex) has also been proven to be the best candidate to extract EPS on activated sludges (Comte et al. 2006). Dowex resin has never been used to extract EPS from benthic diatoms until now except in a recent paper on freshwater sediments (Gersbersdorf et al. 2008). Different 
protocols exist for extracting EPS from intertidal sediments or cultivated benthic diatoms. Sequential extractions are generally used to separate colloidal fraction (after 1 hour in saline solution), $\mathrm{HW}$ fraction (with hot water at 30 or $95^{\circ} \mathrm{C}$ ) and $\mathrm{HB}$ fraction (with hot bicarbonate at 30 or $95^{\circ} \mathrm{C}$ ). Most authors agree that these extracts are not differentiated into clearly defined pools of carbohydrates, but there is a consensus that EPS constitute a continuum of substances more or less tightly associated to the frustule of the benthic diatoms (Wustman et al. 1997; Nielsen and Jahn 1999; Wingender et al. 1999; de Brouwer and Stal 2001; Underwood et al. 2004; Bellinger et al. 2005, Hanlon et al. 2006). According to the pre-treatment of the samples, the pool of internal storage of chrysolaminaran can be solubilised in one or two fractions. For freeze-dried sediments (de Brouwer and Stal 2001; Orvain et al. 2003; Hanlon et al. 2006), this treatment provokes cell lysis and the first fraction (indifferently that the solution was saline or freshwater) is usually contaminated by internal storage compounds. For fresh sediments or cultures of benthic diatoms, the second fraction $(\mathrm{HW})$ is the most contaminated by the pool of internal chrysolaminaran at $30^{\circ} \mathrm{C}$ (de Brouwer et al. 2002) and at $95^{\circ} \mathrm{C}$ (Wustman et al. 1997; Bellinger et al. 2005; Abdullahi et al. 2006). The proportions of glucose are always very high (and almost of the time maximum) in these extracts. The problem of cell lysis has been acknowledged in most studies and such uncertainties limit the conclusion of the studies on EPS.

Extrapolymeric substances are known to be comprised mainly of carbohydrate (Frolund et al. 1996; Chiovitti et al. 2003) but a significant amount of protein has been recorded (Frolund et al. 1996; Staats et al. 1999; Chiovitti et al. 2003). With the exception of warm freshwater extraction, the quantity of protein in the extracts was not significantly different from the control, still reinforcing the idea that the cells were intact with other treatments. Proteins that were found in all these studies were possibly due to the contamination by the internal macromolecules. One of the major roles of EPS production is to readjust the internal equilibrium to hold constant the sugar: protein ratio in case of nutrient stress, this process is named "overflow metabolism" (Staats et al. 2000; Orvain et al. 2003; Underwood et al. 2004). The presence of protein in the EPS composition is incompatible with the assumption of the role of EPS production as an overflow metabolism and must be verified with protocols avoiding cell lysis. Nevertheless, EPS are not only implied in the regulation of metabolic pathway in case of overflow metabolism and some proteins (or glycoproteins) must be secreted with carbohydrates in some conditions. Indeed, proteins are known to contribute to the specific properties of the EPS such as the formation of gel-like structures, the necessity to retain interstitial water (in case of desiccation or nutrient stress for instance), the mediation of adherence to surfaces (a process that is necessary for diatom locomotion), the protection against toxic influences from the environment (Wingender 
et al. 1999). The proportion of secreted proteins in EPS must be associated to the needs of the diatoms for their survival and must drastically change according to the environmental conditions. For instance, we can imagine that there are low rates of protein secretion in case of nutrient stress in the very cell concentrated biofilms and higher rates in case of constitution of new biofilms. Before being able to test such hypotheses, it is very important to use robust methods such as dowex extraction guarantying the integrity of the cells to better define the role played by the protein in the assemblage of the EPS.

It has been reported that high protein: carbohydrate ratio is an indication of protein leakage from lysed cells (Comte et al. 2006). In the present study, the ratio was ten folds higher than ranges 1.6 2.3, reported by Comte et al. (2006) and 3.9 5.1 by Liu and Fang (2002). In the current study, this was true for all extraction methods, including the control, with the exception of freshwater extraction that gave higher values. This result indicates that cell lysis occurred in the freshwater extraction method and not in other extractions. The high background level of protein: carbohydrates ratio must be inferred to the culture medium in which diatoms were grown in, rather than to the EPS themselves. The protein: carbohydrate ratio was slightly lower in dowex buffer than in half salinity extraction method, possibly indicating fewer cell lysis in the dowex resin extraction than in the half salinity extraction.

As described by Azeredo et al. (2003), ATP can be used as an indicator of cell lysis since the ATP molecules can leak through as the membrane becomes permeable. In this study, the amount of ATP obtained for the extraction method of dowex buffer and that obtained for the extraction method using half salinity corresponded with the TEM observation and the ratio between protein: carbohydrate. The ATP level for dowex buffer and half salinity extractions were not significantly different to that of the control, and the TEM images of the diatoms were also similar to the control. In other studies, reported by Nielsen and Jahn (1999), dowex extraction also did not cause cell lysing of bacteria or protozoa.

The chemical methods using fixatives such as GTA and formaldehyde have been known to contaminate EPS (Underwood et al. 1995; Comte et al. 2006). These methods were included in the present study to compare the degree of cell lysis between the protected cells and the non protected cells for dowex and for freshwater treatments. As in previous studies, use of GTA cannot be recommended to extract EPS, not only due to the effect of contamination, but moreover due to the need to dialyze the extracts for removal of GTA, before applying the colorimetric Dubois method to measure carbohydrates. The use of fixative in this study was effective to clearly establish the differences of extraction with or without the protection of cells. The differences between the two extraction methods, of with or without GTA, were clearly apparent on the water 
extracted substances (TEM analysis, immunostaining, proteins and sugar contents) whereas there were no differences observed on the dowex extracts. This reinforces the interest in dowex extraction since the use of dowex resin did not result in significant amount of cell lysis or significantly higher yields of protein extraction when compared to the same extraction after prior treatment with GTA. In contrast, there is significant effect of GTA with water extraction extracts.

Bound EPS that are extracted with dowex are specifically enriched in deoxy sugars with $24.3 \%$ of fucose and $21.4 \%$ of rhamnose. Such characteristics of bound EPS may be related to lack of nutrient stress faced by the diatoms. In contrast, other extraction methods poorly extract these EPS dominated by deoxy sugars. The accurate composition of EPS and the richness in deoxy sugars is very important to understand the properties and the functional role of EPS. EPS enriched in deoxy sugars must be important agents of biostabilisation since they are more surface active than polymers dominated by other monosaccharides (Zhou et al. 1998; Giroldo et al. 2003; Underwood et al. 2004). High proportions of deoxy sugars increases the hydrophobic feature of EPS and this process must influence the degree to which EPS bind to sediments and regulate desiccation (Zhou et al. 1998; Giroldo et al. 2003; Underwood et al. 2004). The proportion of deoxy sugars must also control the retention of water promoting the regulation of the erodability of sediments. In case of nutrient stress, the proportion of glucose must increase with a concomitant decrease in deoxy sugars and this should reduce the hydrophobicity of EPS and thus increase the retention rate of interstitial water at the surficial sediments. This could explain the shift from stabilizing to destabilizing effects of EPS in case of nutrient stress that is described by Orvain et al. (2004). These hypotheses must be verified by using a method extracting EPS with a clear guarantee that there is no internal sugar enriched in glucose contaminating the extracted EPS. The high proportion of deoxy sugars is also an important feature to understand the degradation of EPS by hydrolysis and by bacteria (Giroldo et al. 2003; Hanlon et al. 2006).

Underwood et al. (2004) described 2 pathways of EPS production of differing sugar composition and production patterns: (1) EPS 1 that are dominant EPS produced under nutrient-replete, a complex structure containing all types of sugars, and (2) EPS 2 that are intensely produced in case of nutrient stress and very rich in glucose (maybe due to overflow metabolism). The distinction between these 2 types of EPS is not easy to demonstrate and should be facilitated by using protocols avoiding the emergence of a third pool, the internal carbohydrates.

The present study assessed the efficiency of EPS extraction methods from Navicula jeffreyi culture to minimise other sources of natural EPS from organisms that also live in sediments (bacteria, heterotrophic protist, metazoa). The species studied in the 
present paper is supposed to be a reasonable analogue for other diatoms. The main results converge to show that the cationic dowex resin is the best candidate to extract EPS. This conclusion will be tested on natural intertidal sediments where other species of microalgae coexist in a range of environmental conditions (Orvain et al. in prep).

\section{Conclusion}

All results indicate that freshwater extracts internal storage of benthic diatoms as well as the EPS while other methods did not provoke cell lysis. On the other hand, the second highest EPS content after water extraction was the dowex extraction and this method provided the minimal glucose proportion, coming from internal chrysolaminaran and maximal yield of EPS enriched in deoxy sugars. For these reasons, dowex buffer may be used in the place of water extraction for extracting EPS of benthic diatoms. The quantity of EPS remained low and not significantly different from the control. This minimizes the impact of our conclusion that must be confirmed by another study on sediment biofilms. The effects of extracting reagents can be different on isolated cells and natural matrix as shown by Azeredo et al. (2003) on sludge samples. It is now necessary to make the same kind of comparison on intertidal sediments to verify the robustness of extraction protocol with dowex. Furthermore, the comparison of carbohydrate extraction and their monosaccharide composition will be easier to perform on natural intertidal sediment since the quantities of EPS are considerably higher than in medium cultures. Working with higher quantities of EPS should also improve the results in terms of quantitative assessments of ATP, sugar and protein contents. There is also a need to verify yields of EPS extraction to obtain sufficient amount of EPS which will allow for better quantitative and qualitative analysis on fresh sediments. Dowex resin extraction method must therefore be compared to the freshwater extraction in different environmental conditions and physiological status of the diatoms to clearly establish the advantages and disavantages of both methods and to allow the comparison between studies using different methods.

\section{Acknowledgements}

The authors thank the 2 anonymous referees for their helpful comments and $\mathrm{Dr}$ Anthony Chiovitti for his initial guidance in the study about immunostaining. We are very grateful to Professor M. R. Gretz for his advice about monosaccharide analysis using the GC/MS. We would like to thank Dr Benoit Véron and Mr Bertrand Le Roy of Algobank for supplying us with the diatoms. We also thank Dr Pascal Claquin and Dr 
Sébastien Lefebvre for their advice during cell culturing and Florent Pierre, a student who helped during the preparation of the study. Funding was provided by the National Research Agency (ANR) and this study is a part of the VASIREMI project (Trophic significance of benthic microorganisms in intertidal mudflats) led by Dr Christine Dupuy.

\section{References}

Abdullahi, A.S., Underwood, G.J.C., and Gretz, M.R. (2006). Extracellular matrix assembly in diatoms (Bacillariophyceae). V. Environmental effects on polysaccharide synthesis in the model diatom, Phaedodactylym tricornutum. Journal of Phycology $\mathbf{4 2}$, 363-378.

Azeredo, J., Henriques, M., Sillankorva, S., and Oliveira, R. (2003). Extraction of exopolymers from biofilms: the protective effect of glutaradehyde. Water Science Technology 47, 175-179.

Bellinger, B.J., Abdullahi, A.S., Gretz, M.R., and Underwood, G.J.C. (2005). Biofilm polymers: relationship between carbohydrate biopolymers from estuarine mudflats and unialgal cultures of benthic diatoms. Aquatic Microbial Ecology 38, 169-180.

Chiovitti A., Higgins, M.J., Harper R.,E., and Wetherbee, R. (2003). The complex polysaccharides of the raphid diatom Pinnularia viridis (Bacillariophyceae). Journal of Phycology 39, 543-554.

Chiovitti, A., Molino, P., Crawford, S.A., Ten, R., Spurck, T., and Wetherbee, R. (2004). The glucans extracted with warm water from diatoms are mainly derived from intracellular chrysolaminaran and not extracellular polysaccharides. European Journal of Phycology 39, 117-128.

Comte, S. Guibaud, G., and Baudu, M. (2006). Relations between extraction protocols for activated sludge extracellular polymeric substances (EPS) complexation properties. Part I. Comparison of the efficiency of eight EPS extraction methods. Enzyme and Microbial Technology 38, 237-245.

de Brouwer, J.F.C., Stal L.J. (2001). Short-term dynamics in microphytobenthos distribution and associated extracellular carbohydrates in surface sediments of an intertidal mudflat. Marine Ecology Progress Series 218, 33-44. 
de Brouwer, J.F.C., Wolfstein, K., and Stal, J. (2002). Physical characterization and diel dynamics of different fractions of extracellular polysaccharides in an axenic culture of a benthic diatom. European Journal of Phycology 37, 37-44.

de Brouwer, J.F.C., and Stal, L.J. (2004). Does warm-water extraction of benthic diatoms yield extracellular polymeric substances or does it extract intracellular chrysolaminaran? European Journal of Phycology 39, 129-131.

Decho, A.W. (1990). Microbial exopolymer secretions in ocean environments: their role(s) in food webs and marine processes. Oceanography Marine Biology Annual Review 28, 73-153.

Dubois, M ., Gilles, K.A., Hamilton, J.K., Rebers, P.A., and Smith, F. (1956). Colometric method for determination of sugars and related substances. Analytical Chemistry 28 , 350-256.

Frolund, B., Palmgren, R., Keiding K., and Nielsen, P.H. (1996). Extraction of extracellular polymers from activated sludge using a cation exchange resin. Water Research 30, 1749-1758.

Gerbersdorf, S.U., Jancke, T., Westrich, B., and Paterson, D.M. (2008). Microbial stabilisation of riverine sediments by extracellular polymeric substances. Geobiology 6 , 57-69.

Giroldo, D., Vieira, A.A.H., and Paulsen, B.S. (2003). Relative increase of deoxy sugars ruring microbial degradation of an extracellular polysacchraride released by a tropical freshwater Thalassiosira sp. (Bacillariophyceae). Journal of Phycology 39, 1109-1115.

Hanlon, A.R.M., Bellinger, B., Haynes, K, Xiao, G., Hoffman, T.A. et al. (2006). Dynamics of EPS production and loss in an estuarine, diatom-dominated microalgal biofilm over a tidal emersion-immersion period. Limnology and Oceanography $\mathbf{5 1}$, 79-93.

Liu, H., and Fang, H.P. (2002). Extraction of extracellular polymeric substances (EPS) of sludges. Journal of Biotechnology 95, 249-256. 
Lowry, O.H., Rosebrough, N.J., Farr, A.L., and Randall, R.J. (1951). Protein measurement with the Folin phenol reagent. Journal of Biological Chemistry 193, 265-275.

Nielsen, P.H., and Jahn, A. (1999). Extraction of EPS. In 'Microbial Extracellular Polymeric Substances: Characterization, Structure and Function' (Eds J. Wingender, T.R. Neu and H.C. Flemming) pp 50-72 (Springer-Verlag Berlin Heidelerg, New York)

Orvain, F, Galois, R., Barnard, C., Sylvestre, A., Blanchard, G. et al. (2003). Carbohydrate production in relation to microphytobenthic biofilm development: an integrated approach in a tidal mesocosm. Microbial Ecology 47, 237-251.

Orvain, F., Sauriau, P.-G., Sygut, A., Joassard, L., and Le Hir, P. (2004). Interacting effects of Hydrobia ulvae bioturbation and microphytobenthos on the erodibility of mudflat sediments. Marine Ecology Progress Series 278, 205-223.

Smith, D.J., and Underwood, G.J.C. (2000). The production of extracellular carbohydrate exopolymers (EPS) by estuarine benthic diatoms: the effects of the growth phase and light and dark treatment. Journal of Phycology 36, 321-333.

Spears, B.M., Saunders, J.E., Davidson, I. and Paterson, D.M. (2008). Microalgal sediment biostabilisation along a salinity gradient in the Eden Estuary, Scotland: unravelling a paradox. Marine and Freshwater Research 59, 313-321.

Staats, N., de Winder, B., Stal, L. J., and Mur, L.R. (1999). Isolation and characterization of extracellular polysaccharides from epipelic diatoms Cylindrotheca closterium and Navicula salinarum. European Journal of Phycology 34, 161-169.

Staats N., Stal L.J., and Mur L.R. (2000). Exopolysaccharide production by the epipelic diatom Cylindrotheca clostherium: effects of nutrient conditions. Journal of Experimental Biology and Ecology 249, 13-27.

Underwood, G.J.C., Paterson, D.M, and Parkes, R.J. (1995). The measurement of microbial carbohydrate exopolymers from intertidal sediments. Limnology and Oceanography 40, 1243-1253. 
Underwood, G.J.C., Boulcott, M., and Raines, C.A. (2004). Environmental effects on exopolymer production by marine benthic diatoms: Dynamic, changes in composition, and pathways of production. Journal of Phycology 40, 293-301.

Wingender, J., Neu, T.R., and Flemming, H.C. (1999). What are Bacterial Extracellular Polymeric Substances? In 'Microbial extracellular polymeric substances: characterization, structure and function' (Eds J. Wingender, T.R. Neu and H.C. Flemming) pp 1-15 (Springer-Verlag Berlin Heidelerg, New York)

Wustman, B.A., Gretz, M.R., and Hoagland, K.D. (1997). Extracellular matrix assembly in diatoms (Bacillariophyceae). I. a model of adhesives based on chemical characterization and localization of polysaccharides from the marine diatom Achnanthes longipes and other diatoms. Plant physiology 113, 1059-69.

Zhou, J., Mopper, K., and Passow, U (1998). The role of surface-active carbohydrates in the formation of transparent exopolymer particles in the formation of transparent exopolymer particles by bubble adsorption of seawater. Limnology and Oceanography 43, 1860-1971. 


\section{Tables}

Table 1. Percentage of cells after the seven extraction methods (GTA: Gluteradehyde, ASW: Artificial Sea Water).

\begin{tabular}{llll}
\hline Extraction Methods & $\%$ intact cells & \% damaged cells & \% empty cells \\
\hline no treatment & 75 & 14 & 11 \\
freshwater $30^{\circ} \mathrm{C}$ & 2 & 90 & 8 \\
dowex ASW & 72 & 21 & 7 \\
half salinity & 81 & 11 & 8 \\
GTA dowex ASW & 83 & 11 & 6 \\
GTA dowex water & 79 & 16 & 5 \\
GTA water & 57 & 15 & 28 \\
\hline
\end{tabular}

\section{Figures}

Fig. 1. Flowchart of the extraction procedure. Dowex was used with the combination of phosphate buffer, unless otherwise stated. NT = no treatment, GTA = glutaradehyde $(1.8 \% \mathrm{v} / \mathrm{w})$, dowex $(50 \mathrm{~g} / \mathrm{g})$ 


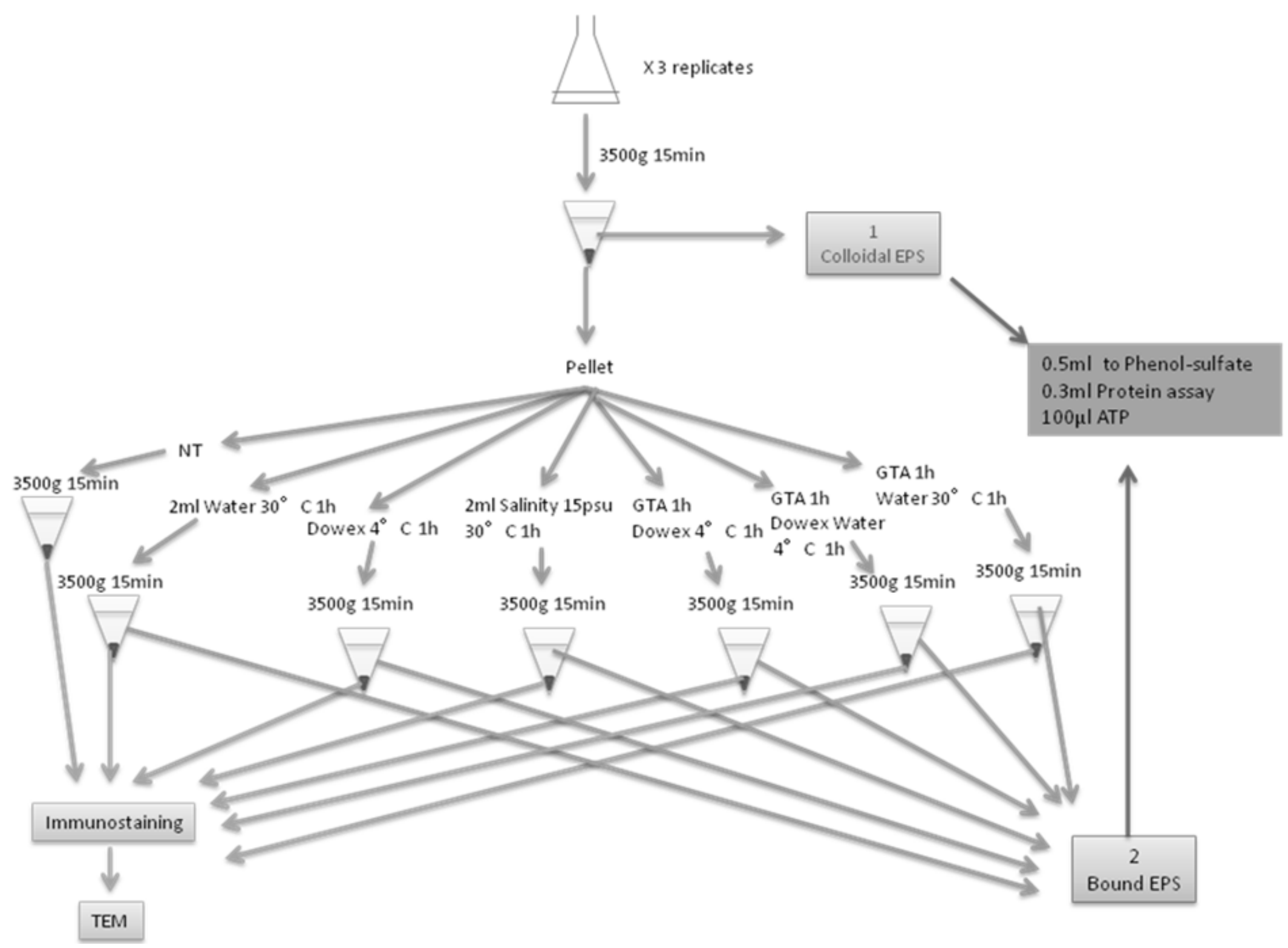




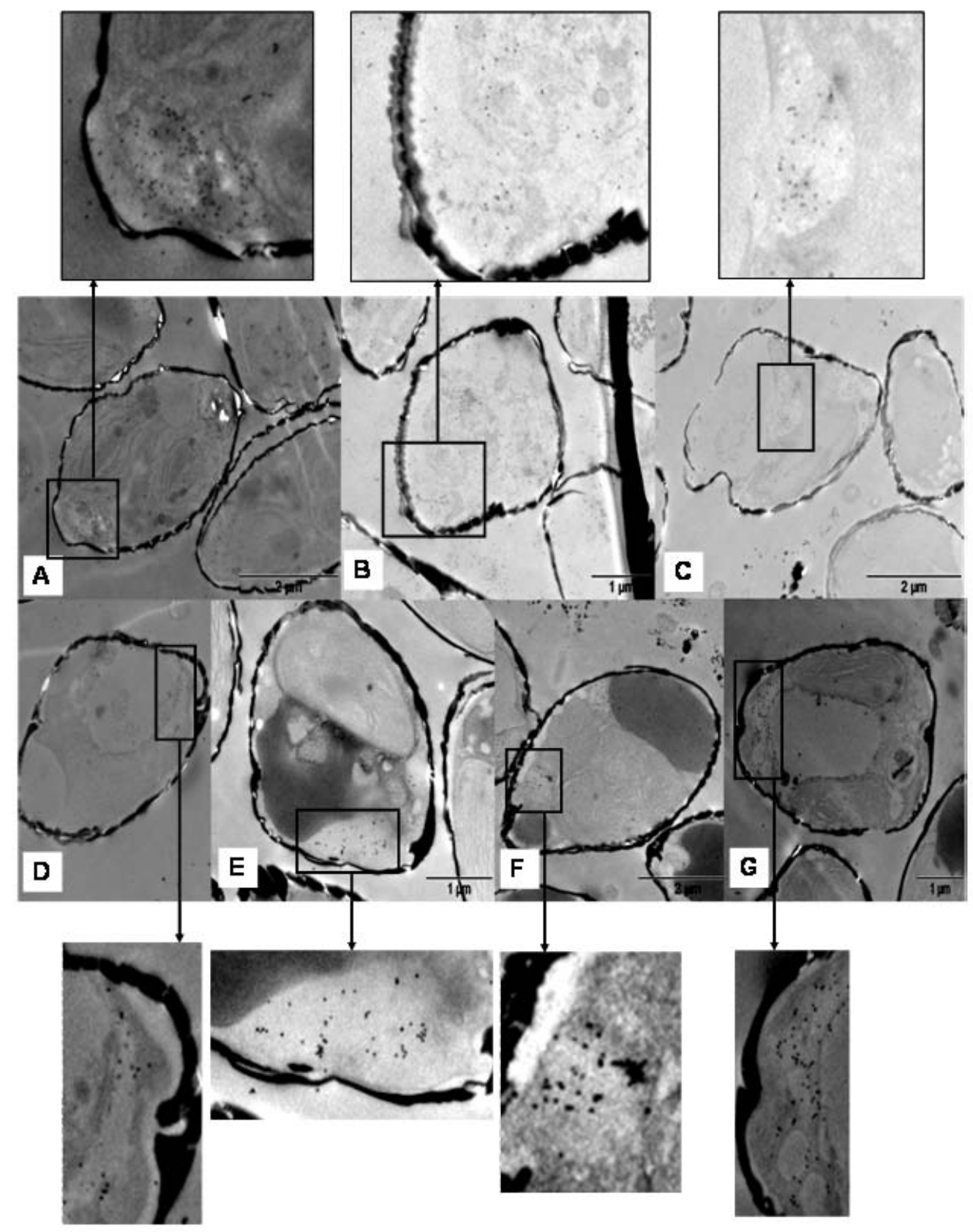

Fig. 2. Transmission electron microscope images of sectioned immuno-stained diatoms Navicula jeffreyi: A) no treatment; B) water treatment; C) dowex buffer; D) half salinity; E) GTA dowex buffer; F) GTA dowex water; G) GTA water. Focus on immunostained vacuoles show the integrity of the vaculole $(A, C, D, E, F, F)$ or the dispersal of internal compounds of the vacuole (B). 


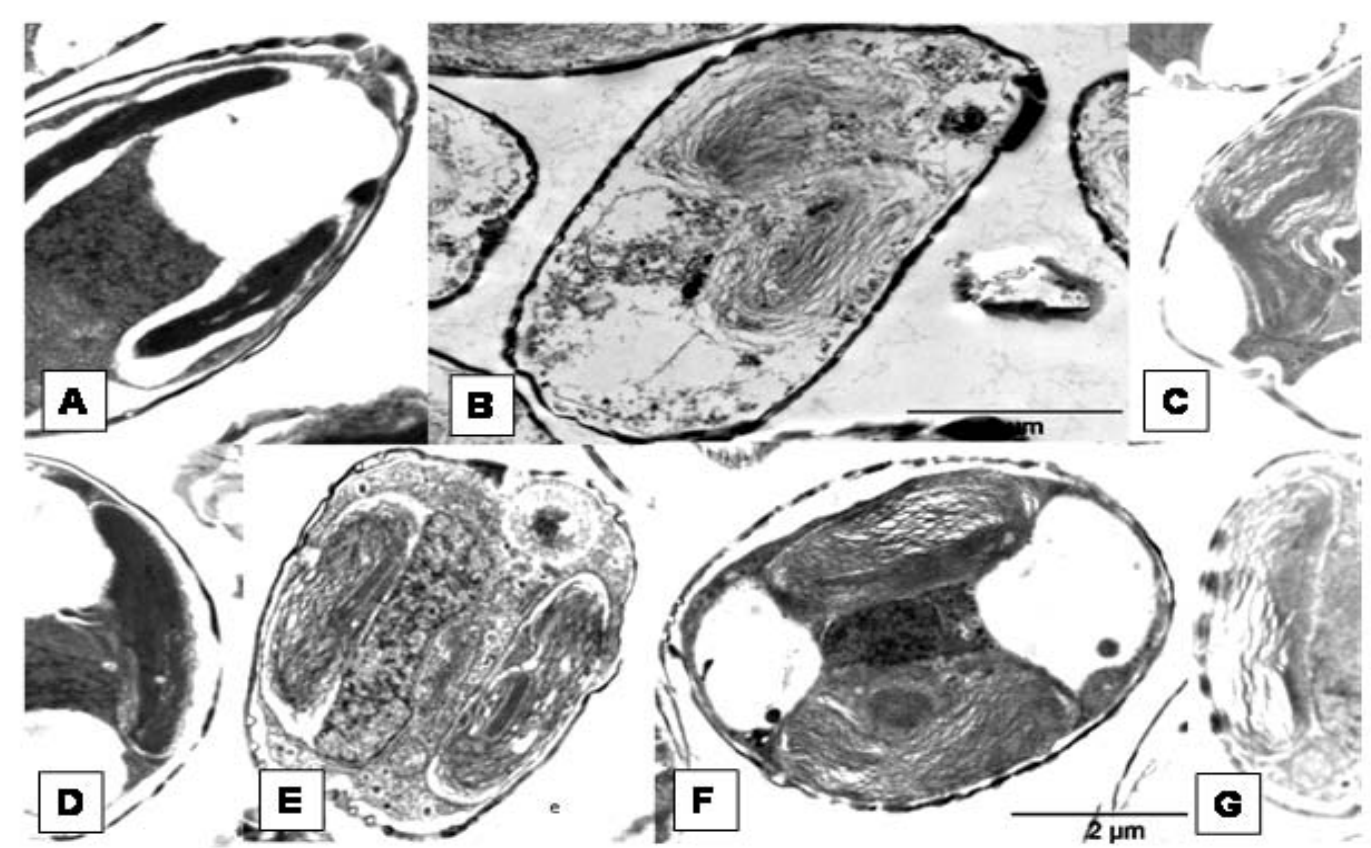

Fig. 3. Contrasted images of Navicula jeffreyi immuno-stained, observed using TEM: A) NT; B) water at $30^{\circ} \mathrm{C}$; C) dowex buffer; D) half salinity; E) GTA water; F) GTA dowex buffer; G) GTA dowex water. 


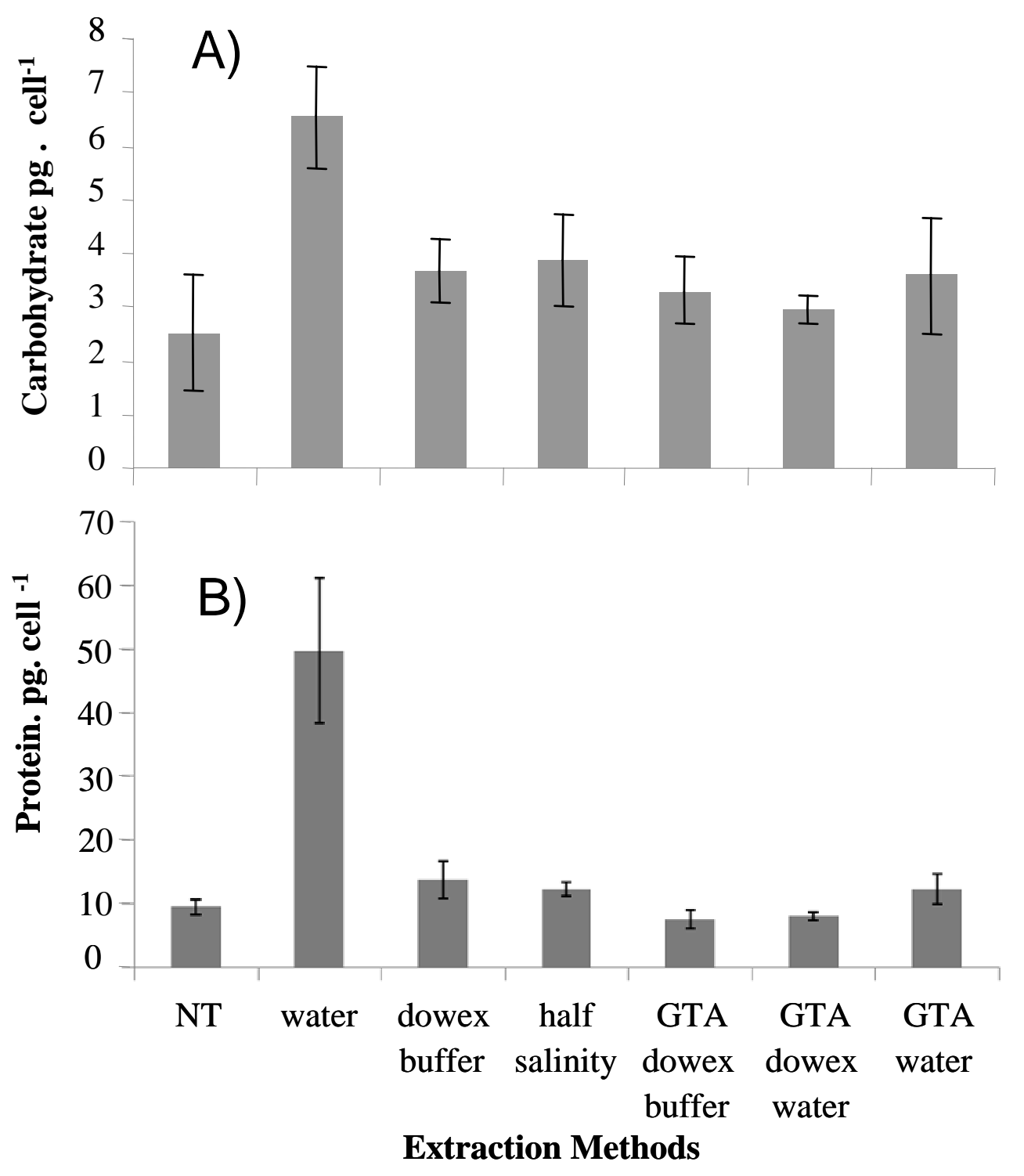

Fig. 4. EPS analysis for each extraction method (bar errors represent standard errors): A) Amount of carbohydrate pg.cell ${ }^{-1}$ measured against glucose standards and B) Quantity of protein in pg.cell ${ }^{-1}$ measured against BSA. 


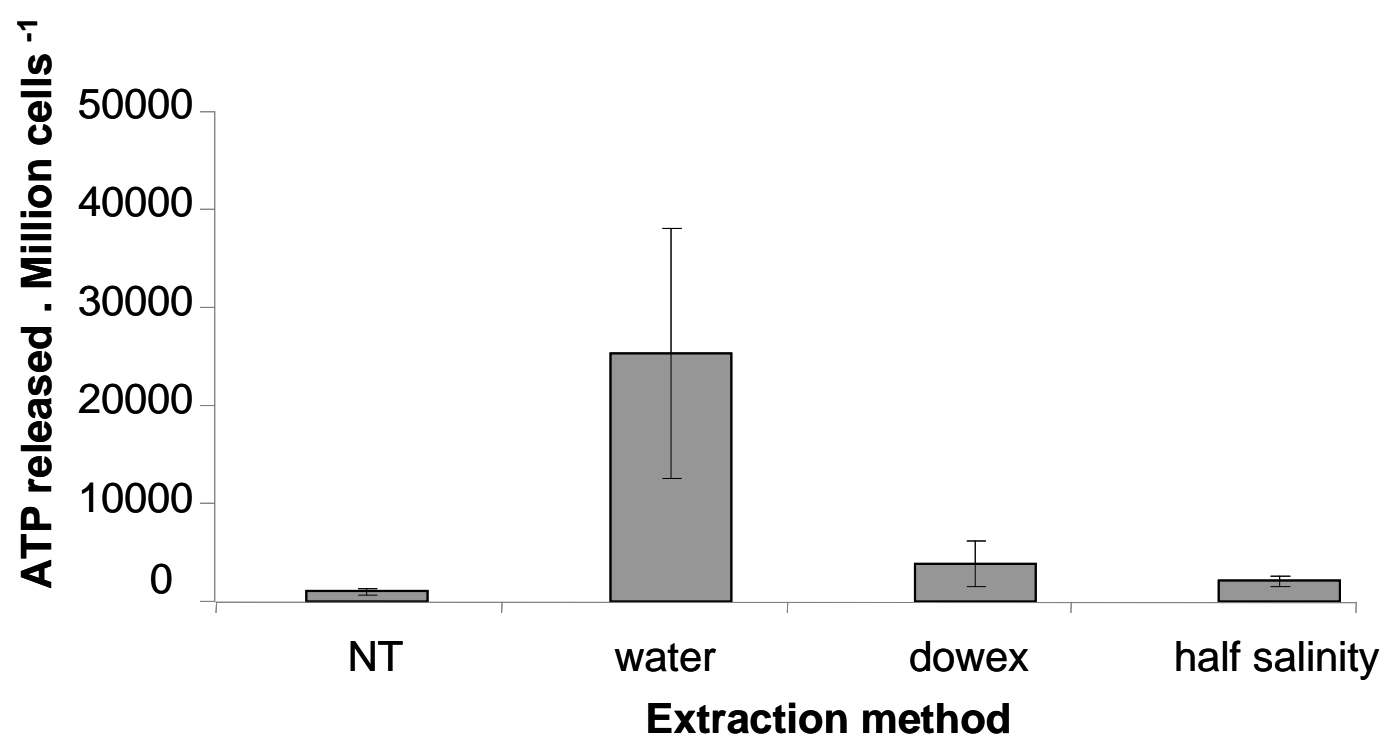

Fig. 5. Quantity of ATP with 4 extraction procedure (bar errors represent standard errors). Extraction with GTA dowex water and GTA water were not shown because the GTA provoked interference with ATP analysis.

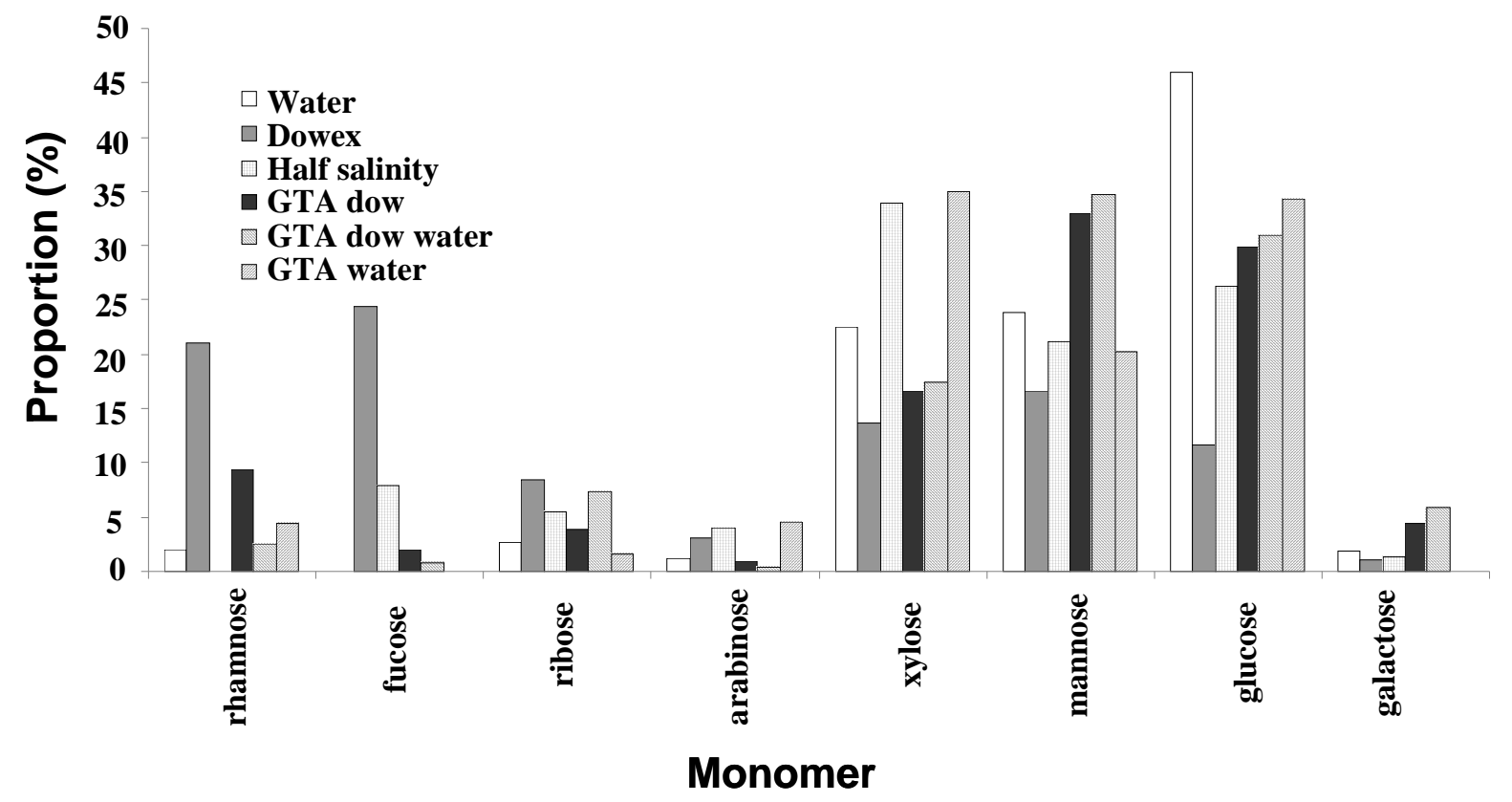

Fig. 6. Monomer fraction of carbohydrated in the bound EPS: comparison between the 6 extraction methods. 